\title{
CONSIDERAÇÕES SOBRE A HISTÓRIA DO PRONOME CONOSCO ${ }^{1}$
}

\author{
OBSERVATIONS ON THE HISTORY OF PRONOUN CONOSCO
}

\author{
Antonio José de Pinho \\ Mestrando do Programa de Pós-graduação em Linguística - UFSC \\ Bruno Cardoso \\ Mestrando do Programa de Pós-graduação em Linguística - UFSC
}

\begin{abstract}
Resumo
Este artigo estuda a evolução do pronome ablativo latino nobiscum que resultou em língua portuguesa na forma conosco. Para isso, busca-se depreender, através de manuais de linguística histórica e de teorias linguísticas, hipóteses, principalmente estruturais, a fim de explicar a transformação do pronome latino na sua forma atual como a conhecemos em português. Além do aspecto histórico, esse artigo descreve ainda a variação sincrônica no uso do pronome conosco, que ocorre em diversos dialetos brasileiros com variantes como com nós e com a gente, baseando-se em dados linguísticos do projeto ALERS.
\end{abstract}

Palavras-chave: Linguística histórica. Variação linguística. Sistema pronominal. Conosco.

\begin{abstract}
This article studies the evolution of the Latin ablative pronoun nobiscum into the Portuguese language resulting form as conosco, translated to the English language as: with us, together with us, regarding us. It thus tries to draw inferences, through Historical Linguistics manuals and linguistic theories, hypotheses, specially structural, in order to explain the transformation of the Latin pronoun into its current form as we know it in Portuguese. Besides the historical aspect, this article further describes the synchronic variation in the use of the pronoun conosco, which occurs in many brazilian dialects with the variants com nós and com a gente, based upon linguistc data of the ALERS project.
\end{abstract}

Key-words: Historical Linguistics. Linguistic variation. Pronominal system. Conosco.

\footnotetext{
${ }^{1}$ Em parte deste artigo (as seções 3 e 4, principalmente) são apresentados os resultados da pesquisa de Antonio José de Pinho, que resultou em seu Trabalho de Conclusão de Curso (TCC), apresentado ao curso de Letras - língua portuguesa e literaturas - no final do segundo semestre de 2009. Este trabalho, com o qual o autor obteve o título de Bacharel em Letras, foi orientado pelo Prof. Dr. Felício Wessling Margotti,. Ao Professor Felício queremos aqui expressar nossa profunda e sincera gratidão, pois foi em suas aulas de História da Língua (disciplina ministrada no semestre 2008/2) que nos surgiu a primeira ideia desta pesquisa, que depois resultou em um trabalho escrito pelos autores para esta disciplina. $\mathrm{O}$ tempo passou, e este tema foi crescendo e apresentando novas facetas cada vez mais fascinantes, muitas das quais ainda esperam ser exploradas devidamente.
} 


\section{INTRODUÇÃO}

Manuais de história da língua portuguesa, como o de Mattoso Camara (1979), apenas descrevem como os pronomes em função de adjunto adverbial de companhia (comigo, contigo, consigo, convosco e conosco) formaram-se e alteraram-se ao longo dos tempos, não indicando as motivações, que estão na própria estrutura da língua, responsáveis pelas alterações na configuração dessas formas pronominais, e, ao simplesmente descrever, não apontam a causa da evolução desses pronomes. Assim, buscando preencher tal lacuna da história do português, procuraremos - com base em elementos da Sintaxe e Dialetologia/Sociolinguística - buscar não apenas uma descrição da origem (e evolução) desses pronomes, porém indicar, ou melhor, explicar a causa da mudança linguística que os originou, principalmente os fatores internos ou estruturais que levaram à atual configuração desses pronomes.

Fica evidente que este é um trabalho essencialmente interdisciplinar, no qual fazemos uso de importantes elementos teóricos de algumas disciplinas da linguística, de tal modo que não nos vinculamos a nenhuma delas exclusivamente. Além do mais, ressalta-se aqui que os dados dialetológicos apresentados mais adiante contribuirão para um embasamento mais empírico e sincrônico do problema, mais especificamente do pronome conosco, no qual centraremos foco. No entanto, o nosso objetivo não residirá em análise de dados empíricos, estes apenas ajudarão a descrever o estado atual da língua no uso do conosco.

Por isso, tal artigo propõe contribuir com os estudos históricos que se debruçaram sobre o tema. Sabemos de muitos estudos sociolinguísticos que têm investigado a variação dos pronomes pessoais na função de sujeito da oração tais como Lopes $(1998,2007)$ e Silva Brustolin (2009). Assim, a variação entre nós/a gente sempre é estudada em contextos como nós falamos/a gente fala. O que podemos afirmar a priori é que o pronome conosco não tem sido tão focalizado nas pesquisas sociolinguísticas quanto, por exemplo, o pronome nós em caso nominativo.

Muito interessante seria estudar essa variação nesse contexto ablativo, uma vez que nesse contexto a disputa pela supremacia entre as formas da língua ganha um novo concorrente, a forma conosco, forma que não existe em função nominativa, como por exemplo:

\section{Ele saiu conosco. \\ Ele saiu com nós. \\ Ele saiu com a gente. \\ Ele veio conosco para a universidade. \\ Ele veio com nós para a universidade. \\ Ele veio com a gente para a universidade.}

Desse modo, para se estudar sincronicamente essa variação, por intermédio de mapeamento de dados das entrevistas do Projeto $\mathrm{ALERS}^{2}$ no Sul do Brasil, será imprescindível iniciar um percurso histórico, que viaje na história do idioma, buscando compreender como essas formas operavam no latim e como se deu a mudança

\footnotetext{
${ }^{2}$ Atlas Linguístico-Etnográfico da Região Sul do Brasil.
} 
linguística resultando nessas construções, ou seja, quais hipóteses que a norteiam. Portanto, não temos aqui a intenção de fazer um trabalho estritamente diacrônico, nem estritamente sincrônico, mas antes uma pesquisa que cruze essas duas perspectivas. Monteiro (2002) diz que a língua existe em função da cultura do povo que dela se serve. As transformações culturais acarretam necessariamente alterações linguísticas, muitas vezes não percebidas pelos falantes no momento em que ocorrem. Para o autor, quando se estuda a língua com a preocupação de levar em conta os aspectos evolutivos, desde suas origens até as mudanças mais recentes, tem-se a perspectiva diacrônica. Ao contrário, caso se escolha para descrição e análise apenas um determinado momento de sua evolução, abstraindo-se todas as conjecturas históricas, adota-se a perspectiva sincrônica. No entanto, como dissemos acima, esse trabalho procura ficar no entrelugar dessas duas perspectivas, o que se coaduna perfeitamente com o que diz o mesmo autor em outro trabalho seu. Monteiro (1989) afirma que

O que talvez seja mais exato é buscar uma integração das duas perspectivas, de tal sorte que a sincronia respeite tanto quanto possivel a verdade diacrônica, fornecendo em troca subsídios para a reconstituição da própria evolução lingüistica. De fato, compreendese facilmente que a diacronia (eixo das sucessividades) é formada por uma multiplicidade de pontos correlacionados aos diversos estágios da língua. Daí, a possibilidade de que uma investigação de natureza sincrônica seja um fator de elucidação de fases anteriores perfeitamente entrelaçadas. A sincronia, sendo resultante de uma cadeia evolutiva, não apenas é capaz de ratificar o que há de historicamente comprovado como também se torna um método de reconstituir formas alteradas ou mesmo desaparecidas.

A própria sociolinguística, segundo Tarallo (1990, p. 81), tem feito grandes esforços no sentido de superar a dicotomia "sincronia versus diacronia" proposta por Saussure, já que na própria sincronia de uma língua podemos encontrar traços de inovação competindo/coexistindo com traços arcaizantes, como mesmo nesse breve estudo será possível se observar nos usos de conosco e suas variantes. Assim, pretende-se aqui ensaiar uma ideia de trabalho mais avançado, uma pesquisa que não se limite a apenas uma perspectiva, mas que se aproprie de ambas a fim de um escavar mais sólido nos mistérios da linguagem humana.

\section{CONOSCO: FONTES PARA UM ESTUDO HISTÓRICO}

A etimologia da forma conosco é comentada por alguns autores tais como Almeida (1962, 1982), Mattoso Camara (1979) e Monteiro (2002) e praticamente não há divergência entre um autor e outro no que diz respeito à forma antiga do pronome conosco.

O primeiro, Napoleão Mendes de Almeida, nas suas duas gramáticas - uma de língua portuguesa e outra de língua latina - discorre sobre o assunto. Em sua clássica Gramática Metódica da Língua Portuguesa, o autor, comentando as origens das formas ablativas migo, tigo, sigo, nosco e vosco, diz que elas provêm do latim mecum, tecum, secum, nobiscum e vosbiscum, palavras compostas da preposição cum e das formas pronominais latinas (cum + me, cum + te, cum + se etc.) colocadas em ordem inversa. 
Comentando essas formas em português, Napoleão afirma que elas vêm outra vez acompanhadas da preposição com (nas formas go e co), como se já não bastasse o cum que as acompanha: com $+\mathrm{mi}+\mathrm{go}(=\mathrm{cum}+\mathrm{me}+\mathrm{cum}), \mathrm{com}+\mathrm{ti}+\mathrm{go}(=\mathrm{cum}+\mathrm{te}+$ cum $),$ com + vos + co (= cum + vobis + cum). Já em sua Gramática Latina, ao falar da preposição portuguesa com, o gramático diz que em latim ela se traduz por cum e rege ablativo, isto é, exige que a palavra posposta a essa preposição venha no ablativo. Tratando de pronomes pessoais, Napoleão afirma que a preposição cum se coloca depois do pronome no ablativo e não antes. Assim, segundo ele, não se dirá, portanto, cum me, cum te, cum se etc., mas mecum (= comigo), tecum (= contigo ), secum (= consigo), nobiscum (= conosco ), vobiscum (= convosco ).

Já Silva Neto (1946, p. 255) em seu livro Fontes do Latim Vulgar apresenta uma edição filológica do Appendix Probi no qual encontramos importantes informações sobre a variedade "popular" do latim que deu origem às línguas neolatinas. Trata-se de uma lista de palavras do latim vulgar as quais são comparadas com as suas equivalentes no latim clássico, sendo interessante notar que são feitas referências ao paradigma pronominal estudado. Citamos abaixo as glosas 220 e 221:

Noviscum non Noscum

Vobiscum nom Voscum

A primeira forma era a que o autor do Appendix considerava correta e a segunda aquela que deveria ser evitada na variedade culta da língua, o que nos indica que as formas noscum e voscum eram estigmatizadas no meio escolar por volta do século III d.C, todavia são estas formas estigmatizadas por Probo que darão origem ao sistema pronominal do português arcaico onde temos as formas nosco e vosco ocorridas isoladamente nas frases: "[...] os sabyos que ouçan os preytos uosco [...]" (LEITE DE VASCONCELOS, 1970, p.38).

Mattoso Camara, na sua obra História e Estrutura da Língua Portuguesa, analisa o sistema de pronomes pessoais. O autor contraria a ideia de que o pronome pessoal conservou em português a categoria de casos do latim, defendendo que o que há no português é uma distribuição de formas, correspondentes. Ele também comenta a regência de preposição com em relação a pronomes pessoais, confirmando a hipótese de Napoleão. Segundo Mattoso, trata-se de vocábulos mórficos em que a preposição se aglutina a um radical:

Migo, tigo, sigo: comigo, contigo, consigo.

Nas palavras do autor, "esse radical já era a aglutinação de cum, enclítico com o ablativo latino $m \bar{e}$, tēe, sēe: migo, tigo, sigo resultam da lenização do $/ \mathrm{k} /$ intervocálico e da metafonia do $-\overline{\mathrm{e}}-(/ \mathrm{e} /)$ por causa do /u/ final em mecu(m), tecu(m), secu(m).'" (p. 97, 1979) Para Mattoso, as formas noscum, voscum, em vez de nobiscum, uobiscum, decorrem de no sistema latino ter-se perdido o dativo-ablativo nobis, uobis, que o latim vulgar substituiu pela forma de nominativo-acusativo $n \bar{s} s, u \bar{o} s$.

Monteiro, em seu livro Morfologia Portuguesa, dedica um capítulo ao estudo da estrutura pronominal da língua. Neste capítulo, o autor aborda a questão do caso e como a supressão do sistema de declinações, que se operou na passagem do latim vulgar para 
o português, atingiu inteiramente a classe dos nomes, mas deixou, segundo ele, alguns vestígios que ainda se observam no emprego dos pronomes pessoais. Há formas pronominais que exercem a função de sujeito (nominativo ou caso reto), a par de outras que se aplicam ao complemento verbal (acusativo e dativo ou caso oblíquo). Para Monteiro, disso surge um problema de análise mórfica: o de saber se as formas do caso oblíquo seriam alomorfes das formas do caso reto. $\mathrm{O}$ autor opta por apelar para o processo de heteronímia.

O linguista termina defendendo a ideia de que o sistema dos pronomes pessoais está sofrendo outras sérias modificações, todas no sentido da eliminação dos vestígios de caso. Cremos que essa hipótese de Monteiro pode ser aplicada também ao pronome em função ablativa conosco, que hoje, na grande maioria dos falantes como os dados do ALERS vão comprovar, se realiza como com nós. No entanto, queremos frisar que não se trata de um apagamento de vestígio de caso dativo, como coloca o autor, e sim de caso ablativo, tendo em vista que estas formas se realizam em função sintática de adjunto adverbial.

\section{A MOTIVAÇÃO ESTRUTURAL DA MUDANÇA}

\subsection{Analogia e regularização do paradigma}

Descrever como a língua muda não é o bastante, é preciso explicar a causa. E há, pelo menos, três explicações para a mudança de nobiscum - no latim - para conosco e, consequentemente, para com nós/com a gente. Em primeiro lugar, sabemos que as línguas do tronco indo-europeu, pelo menos, no decorrer de suas histórias, tendem desde muito tempo para uma simplificação de suas estruturas morfológicas; isso é percebido facilmente nos sistemas de flexão casual. No indo-europeu, os nomes declinavam-se em oito casos. Portanto, havia nele mais dois casos do que no latim, a saber, o locativo e o instrumental que foram substituídos por um maior uso de preposições.

E a ausência do locativo e do instrumental, em latim, coincide justamente com o aparecimento de preposições que não existiam no sânscrito, onde, no entanto, persistiam aqueles dois casos. (MONTEIRO, 1926, p.17)

No próprio latim clássico, o sistema de flexão casual já apresentava sinais de simplificação, pois os casos nominativo e vocativo se neutralizavam em quase todas as declinações, menos na segunda (ex.: dominus, domine). Além disso, o ablativo e o dativo também tinham a mesma forma na maior parte das declinações (ex.: domino, domino).

Sendo assim, como na sociolinguística temos o princípio da uniformidade (TARALLO, 1990, p. 81), segundo o qual as mesmas forças observadas na sincronia de uma língua também, provavelmente, ocorreram no passado, temos que ver que não é por acaso que o português atual caminha para uma realidade em que há menos flexões verbais e menor quantidade de marcas de caso no sistema pronominal. Segundo Mattoso Camara (1979, pág. 72 e 73) o mesmo ocorreu com o latim em que o sistema flexional verbal e nominal 
simplificou-se com a supressão de vários casos e desinências. Assim podemos ver que as mudanças linguísticas ainda atuam no sentido de apagar as desinências. Ou ainda, o atual caminho percorrido pelo português é, na verdade, a continuação de várias mudanças estruturais que já ocorreram no português e, antes, no próprio latim.

A passagem do conosco, prescrito pela norma padrão, para as formas com nós e com a gente pode muito bem ser explicada por esse processo histórico de perda das marcas de caso no sistema morfológico da língua, porque, como foi explicado antes, o pronome nosco, que sempre ocorre aglutinado à preposição com, nada mais é que um resquício do caso ablativo no sistema pronominal do português.

A segunda explicação da mudança se deve à tendência de regularização dos paradigmas gramaticais, o que, na verdade, é uma consequência do processo descrito acima. A regularização ocorre também por analogia, pois se o falante usa estas variantes:

\section{Nós cantávamos $>$ A gente cantava \\ Isso é nosso > Isso é da gente \\ Ele $\underline{\text { nos }}$ viu $>$ Ele viu a gente}

num processo de analogia, ele certamente pode colocar, também, o pronome a gente em posição de adjunto adverbial de companhia precedido pela preposição com. O mesmo vale para o uso da variante com nós.

Nós cantava
Ele viu nós

Assim, nada impede a frase Ele saiu com nós. O falante, por analogia, regulariza o seu paradigma pronominal de primeira pessoa do plural, apagando as marcas de caso acusativo (Ele viu nós) ao colocar o pronome do caso reto em posição de objeto direto, e, também, ao eliminar os resquícios de ablativo substituindo nosco por nós, do caso nominativo. Entretanto, levando em conta a avaliação social das variantes, a variedade não-padrão, que utiliza nós, encontra-se em desvantagem, já que muito possivelmente conta com estigma. Podemos intuir, pela nossa própria experiência como falantes da língua, que quem falar com nós em uma reunião de trabalho ou para uma grande plateia será avaliado negativamente. Por outro lado, a variante com a gente é mais neutra nesse sentido, pois não é tida como "errada" pelo vulgo.

\subsection{A motivação sintática}

Mudando, agora, um pouco o foco da análise, vemos que há profundas implicações sintáticas na transição do latim nobiscum para conosco no vernáculo.

Em uma oração simples com sujeito e um predicado com verbo transitivo, há seis possibilidades de combinação dos sintagmas, sendo elas: SVO, SOV, VOS, OVS, OSV e VSO. Dessas possibilidades, segundo Slobin (1980), nas línguas naturais encontramse apenas três delas: as estruturas SVO (como no português, espanhol e inglês), SOV (como no latim clássico) e VSO. 
Pode-se ver também que, seja qual for a língua, o verbo pode aparecer em qualquer posição, mas os sintagmas nominais não, pois o sujeito precede o objeto direto. Claro que em latim havia grande liberdade de posicionamento dos sintagmas, como confirma o próprio Mattoso Camara (p. 72) em sua história da língua portuguesa, mas os gramáticos, como Almeida (1982), recomendam o uso da ordem clássica SOV.

$$
\begin{array}{ccc}
\text { Luna } & \text { terram } & \text { illustrat. } \\
\mathrm{S} & \mathrm{O} & \mathrm{V}
\end{array}
$$

Tal ordem sintática não impede as outras combinações possíveis entre os sintagmas, isso pelo motivo de a morfologia nominal marcar no nome a sua função na oração. Vejamos:

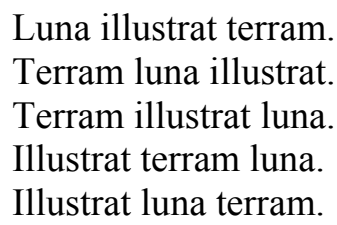

Em todas as opções sabemos perfeitamente a função sintática de cada substantivo, não importando em que ordem esteja. Isso podia ocorrer em latim, principalmente na poesia, para que os versos seguissem a métrica e o ritmo desejado. $O$ que não anula, obviamente, o fato de o latim ser uma língua de estrutura sintática SOV.

Devido à morfologia nominal simplificada na evolução da língua, a mesma sentença em português tem somente a seguinte estrutura:

$\begin{array}{ccc}\text { A lua } & \text { ilumina } & \text { a terra. } \\ \mathrm{S} & \mathrm{V} & \mathrm{O}\end{array}$

Slobin reproduz em seu livro uma tabela na qual estão os resultados de um estudo de J. A. Hawkins ${ }^{3}$ que faz a correlação entre a existência de posposição ou preposição e a estrutura sintática, vendo qual a influência que a ordem sintática pode ter sobre a colocação da preposição (ou posposição) em relação ao sintagma que rege.

TABELA 1. A relação entre ordem sintática e a ocorrência de preposição ou posposição

\begin{tabular}{l|c|c|c}
\cline { 2 - 4 } & \multicolumn{3}{c}{ Ordem dominante de palavras } \\
\cline { 2 - 4 } & VSO & SVO & SOB \\
\hline Preposições & 38 & 60 & 5 \\
\hline Posposições & 1 & 23 & 90 \\
\hline
\end{tabular}

Fonte: (HAWKINS apud SLOBIN, 1980, p. 95)

Sendo assim, logo se percebe que as "línguas do tipo SVO variam, mas 73 por cento delas usam preposições" (SLOBIN, 1980, p. 96). Este é o caso das línguas neolatinas como o português e o espanhol. Além do mais, o estudo de Hawkins é muito significativo por ter sido feito com base em 217 línguas, de acordo com sua estrutura

\footnotetext{
${ }^{3}$ Segundo se pode ver na bibliografia do supracitado livro de Slobin, Psicolinguistica, este estudo de J. A. Hawkins, que por sinal não foi publicado, foi apresentado em 1976 na Universidade da Califórnia sob a forma de comunicação.
} 
sintática, ou seja, do posicionamento da preposição (ou posposição) em relação ao sintagma que está regendo. Mais de duas centenas de línguas é uma amostra bem significativa, com a qual é possível lançar um novo olhar sobre o problema da evolução dos pronomes em português.

Como indica a tabela, de um total de 114 línguas que possuem posposições, 90 delas têm a ordem sintática na qual o objeto direto precede o verbo que ocorre ao fim da oração, o que significa dizer que $95,7 \%$ das línguas SOV, como é o caso do latim, possuem posposições. Assim, em termos de estrutura sintática, a possibilidade de a língua latina possuir posposições era bem maior do que não possuir, e é o que de fato ocorria em tal idioma, lembrando que a posposição não era um fato absoluto no latim. $\mathrm{Na}$ verdade, é que ela não ocorria na maior parte dos casos uma vez que em latim havia a coexistência tanto das preposições quanto das posposições. Porém, o que mais significa, no presente caso, é a presença ou não de posposições dentro da estrutura linguística. Um fato inquestionável é que esta variação estrutural na qual havia tanto posposições quanto preposições deixou de existir no português e no espanhol, para que houvesse exclusivamente a preposição. E, juntamente, um dos fatos sintáticos significativos na passagem do latim ao português ${ }^{4}$ foi a mudança da ordem sintática SOV para a atual SVO, o que significa que se passou de uma estrutura sintática que privilegiava a ocorrência de posposições para uma que privilegia a preposição.

Os dados da tabela de Hawkins demonstram - além do que foi dito a respeito das línguas SOV - que, contrariamente às línguas do tipo do latim que contam com posposições, as línguas, cujo objeto direto aparece ao fim da oração e sucede o verbo, apresentam muito mais possibilidade de terem preposições. Obviamente elas variam mais que as línguas de posposição, mas, de um total de 103 línguas de preposição estudadas por Hawkins, 60 delas possuem a ordem sintática SVO, resultando numa porcentagem de quase $60 \%$. Ou seja, neste caso também há certa tendência de a estrutura sintática determinar o posicionamento das preposições, o que se confirma com as línguas SVO quando estas apresentam uma maior possibilidade de ter preposição que posposição, ainda mais se pensarmos que a posposição em latim ocorria só em parte de sua estrutura gramatical.

Nada impede de se argumentar que a mudança da ordem SOV do latim para a ordem SVO do português tenha sido a causa estrutural de uma profunda mudança na configuração dos pronomes em posição de adjuntos adverbiais (conosco, comigo, consigo...). A possibilidade de que o português continuasse a ter posposições após a mudança da estrutura sintática era absolutamente pequena, porque apenas $27 \%$ das línguas SVO são de posposições, considerando-se obviamente o universo de línguas pesquisadas por Hawkins, levando-nos à conclusão de que apenas 23 línguas, de um total de 83 de tipo SVO, possuem posposições.

Sintetizando tais números, basta se afirmar que há muito mais possibilidades de uma língua SVO possuir preposição do que posposição. E, no caso contrário (que é o caso do latim), há muito mais possibilidade do uma língua SOV ter posposição do que não ter. Pode-se entender, assim, com base em tais números, que a mudança sintática operada na passagem do latim ao português, na qual houve a posposição do objeto

\footnotetext{
${ }^{4} \mathrm{E}$ também às outras línguas neolatinas.
} 
direto ao verbo da oração, tenha imposto uma nova configuração da estrutura dos pronomes do paradigma de conosco.

O mais importante é que essas línguas de ordem sintática SOV, possivelmente por imposição estrutural da gramática universal, como acabamos de ver, privilegiam a existência de preposições em posposição ao sintagma nominal que regem. (SLOBIN, 1980) É justamente isso que ocorre nos sintagmas mecum, secum, tecum, nobiscum e vobiscum, onde a preposição aparece após os pronomes, formando a seguinte estrutura sintática:

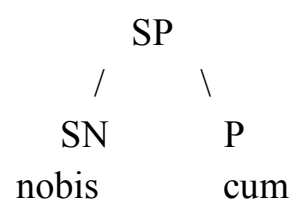

De acordo com Tarallo (1990), à clássica ordem SOV do latim clássico, sucedeu-se uma estrutura de transição OVS, em latim vulgar. Mas essa é apenas uma hipótese de T. Givón, autor de um artigo citado por Tarallo (1990, p.152), e não algo comprovado. No entanto em verbos intransitivos, que formam frases com estrutura sintática completamente diferente, é bem razoável admitir a ordem verbo-sujeito. Porém, na passagem do latim ao português arcaico, houve a inversão dos sintagmas passando a existir a ordem sujeito-verbo. Em português arcaico ainda havia a variação entre a ordem verbo-sujeito e sujeito-verbo, mas esta última foi se tornando cada vez mais presente na língua, como afirma Tarallo (1990, p. 152).

Tais fatos sintáticos indicam que em português arcaico existiam muitas marcas sintáticas do latim vulgar. Assim, é compreensível haver as formas migo, tigo e sigo usadas isoladamente em português arcaico, porque a estrutura da língua ainda estava em fase de transição, conservando traços arcaizantes em sua gramática. Nesse caso específico, a posposição da preposição com, que neste estágio da evolução linguística já estava bem alterada com a troca do $c$ pelo $g$ e, ainda, com apócope do segmento $m$, além da metafonia ocorrida na última vogal (cum $>\mathrm{cu}>*_{\mathrm{gu}}>$ go). Mas, mesmo com todas essas alterações na forma, ainda exercia sua função de preposição dentro do paradigma atribuindo o caso ablativo ao pronome que o antecedia.

O mesmo pode ser dito para a forma conosco, já que faz parte do mesmo paradigma que as formas contigo, consigo etc. Na passagem do latim clássico ao vulgar (CAMARA JUNIOR, 1979, p. 98) houve a troca do nobiscum por noscum para a regularização do sistema, como já foi dito, fato que se deu por analogia, havendo o mesmo processo hoje, em que se dá a troca do conosco pelo com nós.

Portanto, no português arcaico as formas pronominais migo, tigo, sigo, nosco e vosco tinham uma estrutura sintática inversa da encontrada no português moderno, pois a preposição ocorria aglutinada ao fim, como vimos. Mas a mudança sintática que substituiu a ordem clássica SOV por SVO também levaria a um rearranjo no sistema dos pronomes em função de adjunto adverbial de companhia, passando a ser necessária a introdução da preposição com diante dessas formas pronominais. 
Se formos analisar em um diagrama arbóreo, passaríamos a ter a seguinte estrutura sintática:

\begin{tabular}{rl}
\multicolumn{2}{c}{ SP } \\
\multicolumn{1}{c}{$\quad l$} \\
$\mathrm{P}$ & $\mathrm{SN}$ \\
co & nosco \\
com & a gente \\
com & nós
\end{tabular}

Um outro fato digno de nota da história do pronome conosco é que em espanhol já não se possuem resquícios de caso ablativo em sua forma atual, e isso no próprio espanhol padrão, ou seja, o espanhol usado em sua modalidade escrita. Fato que por si só demonstra que o apagamento do sistema de casos atuou neste ponto da gramática espanhola há muito tempo, sendo que a forma connosco existia em estágios passados da história do idioma castelhano. O pronome é hoje, a saber, con nosotros, onde nosotros é o nosso nós, e resultou da junção das formas nos (pronome do caso nominativo) ao vocábulo outros. O interessante é que a formação con nosotros é estruturalmente idêntica à portuguesa não-padrão com nós, ou seja, temos nas duas línguas a preposição $\mathrm{com} / \mathrm{con}$ precedendo o pronome do caso reto nós/nosotros. Tanto no português quanto no espanhol as mudanças linguísticas ocorreram - e também agora estão ocorrendo num mesmo sentido: a completa eliminação de resquícios de caso ablativo. Há tempos tal mudança aconteceu no espanhol e apagou essa herança morfológica vinda do latim. Hoje no português falado no Brasil a batalha ainda não cessou, e as três variantes estão em plena disputa. Contudo, como a próxima parte deste texto mostrará, dados empíricos evidenciam que o idêntico processo, que eliminou essa forma pronominal ablativa do espanhol, também a está eliminando do português.

Eis aqui a confirmação do principio da uniformidade do qual anteriormente fizemos referência: "as forças que atuam no momento presente, o do ponto de partida, são provavelmente as mesmas que teriam atuado ou estariam atuando no ponto de desembarque." (TARALLO, 1990, p. 81) No caso presente, trata-se de uma força interna da língua, ou seja, uma força proveniente de sua própria estrutura gramatical da qual acabamos de tratar.

\section{A SINCRONIA E VARIAÇÃO DIATÓPICA}

Passemos, agora, a analisar a língua portuguesa em sua sincronia, tendo como base dados fornecidos pela geografia linguística.

Como inúmeros estudos diacrônicos e sociolinguísticos mostram, as línguas naturais apresentam uma tendência à regularização das formas gramaticais, como já foi visto. Tal fenômeno fica ainda mais evidente no componente morfológico da gramática. Isso significa dizer que, na maior parte das vezes, a história de uma língua (como o português) pode ser entendida como a histórica diminuição das flexões verbais e nominais. A história das línguas neolatinas demonstra muito bem nossa afirmação, na medida em que a regularização do rico sistema casual latino alterou drasticamente a 
morfologia dos nomes, tanto que apenas um caso restou dos seis do latim. No português e espanhol, sobreviveu somente o caso acusativo, e no italiano o nominativo.

No sistema dos pronomes em função de adjunto adverbial não ocorre algo muito diferente do que aconteceu (e continua acontecendo) com os outros paradigmas verbais ou pronominais. É bem do conhecimento dos linguistas lusófonos - ou de outros estudiosos do assunto - que a entrada de novos pronomes (você, vocês e a gente) na posição de sujeito simplificou ou regularizou profundamente o sistema flexional dos verbos. Estes pronomes também alteraram o paradigma do conosco, visto que com você substituiu contigo em vários dialetos do português, e a generalização do uso de com vocês tomou o lugar do clássico convosco.

O corpus do ALERS pode muito bem, em relação ao uso do sintagma conosco, lançar uma luz sobre a variação diatópica na sua sincronia. E não apenas isso, os dados disponíveis nesse atlas linguístico podem revelar uma tendência de mudança no português de grande parte do território brasileiro.

Como o ALERS busca registrar as variedades dialetais dos estados meridionais brasileiros, consequentemente apresentamos dados do Paraná, de Santa Catarina e do Rio Grande do Sul. Ressaltemos que o inquérito do ALERS foi aplicado focando mais as regiões rurais que as urbanas; por isso há mais pontos pesquisados no contexto rural do que no urbano e em cada ponto foi entrevistado um informante.

Abaixo está uma tabela na qual são mostrados os dados empíricos registrados pelo ALERS em meio rural somente. Nessas regiões rurais foram pesquisadas 100 localidades do Paraná, 80 de Santa Catarina e, finalmente, 95 do Rio Grande do Sul.

As três variantes - com nós, com a gente e conosco - foram registradas no sul do Brasil. Com efeito, a variante mais difundida geograficamente pelo sul do Brasil, em meio rural, é com nós, perfazendo um total de $72,36 \%$ de uso da variante nesses três estados. E esta variante do conosco, ao que tudo indica, não pode ser classificada como estando intimamente vinculada a este ou àquele dialeto, pois seu uso é muito difundido nos três estados do sul.

TABELA 2. Porcentagens na variação entre as formas conosco, com nós e com a gente nos três estados do sul do Brasil em regiões rurais.

\begin{tabular}{l|l|l|l|l}
\cline { 2 - 5 } & Paraná & Santa Catarina & Rio Grande do Sul & Total \\
\hline conosco & $10 / 100=10 \%$ & $12 / 80=15 \%$ & $22 / 95=23,16 \%$ & $16 \%$ \\
\hline com nós & $70 / 100=70 \%$ & $63 / 80=78,75 \%$ & $66 / 95=69,5 \%$ & $72,36 \%$ \\
\hline com a gente & $1 / 100=1 \%$ & $0 / 80=0 \%$ & $2 / 95=2,1 \%$ & $1,1 \%$ \\
\hline $\begin{array}{l}\text { Dados não } \\
\text { obtidos }\end{array}$ & $11 / 100=11 \%$ & $15 / 80=18,75 \%$ & $5 / 95=5,26 \%$ & $11,27 \%$ \\
\hline
\end{tabular}

Fonte: (PINHO, 2009, p. 52)

Destaquemos, aqui, que o ALERS registra que, em vários pontos (dezessete no total) os informantes utilizaram a forma padrão conosco, mas também a não-padrão com nós. Esse fenômeno mostra que muitos dominam as duas variantes, ou seja, conosco e com nós estão registradas na sua gramática interna, portanto, na sua competência. Porém o 
uso (a performance do falante) de uma ou de outra variante vai depender de fatores externos, como o grau de formalidade em que a pessoa estiver ou a sua posição hierárquica em relação ao interlocutor - se é superior ou inferior a este. Supomos, obviamente, que a variante padrão conosco seja utilizada em momentos de elevadíssimo grau de formalidade e monitoramento, em contexto rural no sul. Contudo, deixemos claro que tal afirmação não passa, no fundo, de uma suposição, porque a natureza dos dados do ALERS não nos permite sustentá-la com absoluta certeza. Apenas a pequena taxa percentual de ocorrência de conosco revela que essa forma possui um uso muito restrito, e esse uso deve se dar em situações conversacionais bem determinadas, como o maior ou menor distanciamento entre os interlocutores, a posição social destes, ou, ainda, o grau de formalidade da situação, lembrando que tal fato ainda carece de uma comprovação empírica.

Pode se tratar muito mais de uma verdadeira variação diafásica do que diatópica, nesse caso, ou seja, o fator geográfico tem menor importância do que o fator diafásico situacional - na variação. Contudo, segundo as porcentagens da tabela acima, há indícios de uma pequena correlação entre a variação no uso do conosco e o espaço geográfico. Vemos claramente que, quanto mais ao sul, maior é a ocorrência de conosco. Dessa forma o Paraná apresenta a menor taxa no uso dessa variante, apenas $10 \%$, ou melhor, ocorreu em dez pontos, num total de cem. No outro extremo, temos o Rio Grande do Sul com a mais elevada porcentagem de ocorrência dessa variante, ou seja, houve pouco mais de $23 \%$ de uso de conosco, configurando um total de vinte e dois pontos. Já o estado de Santa Catarina ficou numa posição intermediaria entre os outros dois, havendo o registro de doze ocorrências da forma conosco, totalizando uma média de $15 \%$. Assim como o estudo de Pinho e Margotti (2009), este breve trabalho acaba confirmando

as afirmações de Altenhofen (2002) que entendeu o território catarinense como uma região de transição entre padrões dialetais tipicamente gaúchos, de um lado, e paranaenses, de outro. (PINHO; MARGOTTI, 2009, p. 61)

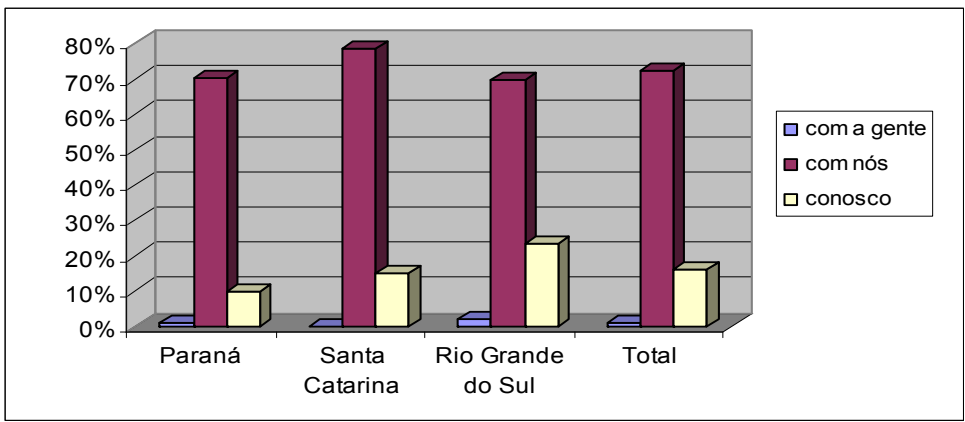

GRÁFICO 1. Variação entre com nós, com a gente e conosco no sul do Brasil em regiões rurais Fonte: (PINHO, 2009, p. 53)

Em suma, percebemos que, na esfera da variação diatópica da língua portuguesa em suas variedades faladas no sul do Brasil, uso da forma com a gente é muito restrito em meio rural, apenas há três registros, num total de 275 localidades pesquisadas, resultando numa média de apenas $1,1 \%$. Já a forma com nós que, inclusive, é estruturalmente mais regular e forma um sistema mais simplificado do que a forma 
prescrita pela norma padrão, possui uma difusão muito maior pelo espaço geográfico do que as outras variantes.

Como vimos que o fator espaço geográfico pouco influenciou na variação entre conosco, com nós e com a gente, é muito provável que a variante mais difundida no sul do Brasil também seja muito presente em outras variedades dialetais do português de diferentes regiões do território nacional. Mas somente a finalização do projeto $\mathrm{ALiB}^{5} \mathrm{e}$ futuros trabalhos interpretativos poderão indicar com muito maior precisão para onde se direciona o português do Brasil (PB), ou seja, se para a manutenção do conflito entre as três formas, ou para uma mudança linguística em que a forma clássica conosco saia da gramática devido ao seu baixíssimo uso. Nessa última hipótese, ainda as formas com nós e com a gente estariam em disputa. Mas qual delas prevalecerá no português brasileiro? Eis uma pergunta que, por ora, não possui resposta.

Contudo, de qualquer maneira, compreendendo que o português está evoluindo no sentido da eliminação dos resquícios de caso em seus paradigmas pronominais (MONTEIRO, 1994), não é precipitada a afirmação de que o pronome conosco tende, mais cedo ou mais tarde, a se tornar uma forma arcaica do português brasileiro.

\section{CONCLUINDO}

Buscamos, neste estudo, efetuar uma junção entre a perspectiva diacrônica ${ }^{6}$ e a sincrônica para que a análise pudesse problematizar e aprofundar mais a abordagem de nosso objeto de estudo. Vimos, portanto, as várias etapas da evolução dos "pronomes adjuntos", mais especificamente a evolução da forma conosco. Colocando as várias formas que esse pronome teve, no decorrer da história da língua, em uma cadeia evolutiva, temos: nobiscum $>$ noscum $>$ noscu $>$ nosco $>$ conosco $>$ com nós $>$ com a gente.

Procuramos deixar claro que as mudanças no paradigma dessas formas pronominais adjuntas ocorreram no sentido de um apagamento dos resquícios das marcas do caso ablativo dentro do sistema gramatical. Portanto, diversos fatores levaram à regularização das formas por processos de analogia, dentre outros fenômenos possíveis.

Também relacionamos esses processos de variação linguística com a sintaxe. Defendemos a hipótese segundo a qual mudanças linguísticas que atuaram sobre a estrutura sintática do latim e do português causaram uma reorganização do sistema dos pronomes regidos pela preposição com.

Por último, fizemos uma análise sincrônica da variação do pronome tendo como corpus o ALERS. Ficou evidente que a variante mais difundida em todo o sul do Brasil é com nós. Já a variante padrão tem uso muito restrito e este tende a aumentar em direção ao sul, sendo que no Rio Grande do Sul houve maior presença de conosco. Também pudemos detectar que a variante com a gente, mesmo não contando com estigma, tem pequena presença nas variantes do português falado nos três estados brasileiros do sul.

\footnotetext{
${ }^{5}$ Atlas Linguístico do Brasil.

${ }^{6}$ Entendemos neste trabalho diacronia como uma sucessão de sincronias, como já defendia Saussure em seu Curso de Linguística Geral.
} 


\section{REFERÊNCIAS}

ALMEIDA, Napoleão Mendes de. Gramática metódica da língua portuguesa. 14 ed. São Paulo: Saraiva, 1962.

. Gramática latina. 18 ed. São Paulo: Saraiva, 1982.

ALTENHOFEN, Cléo Vilson. Áreas lingüísticas do Português falado no sul do Brasil: um balanço das fotografias geolingüísticas do ALERS. In: VANDRESEN, Paulino (org.). Variação e mudança no Português falado da região sul. Pelotas: EDUCAT, 2002.

ATLAS LINGÜÍSTICO-ETNOGRÁFICO DA REGIÃO SUL DO BRASIL (ALERS). Volume 1: Introdução; Volume 2: Cartas Fonéticas e Cartas Morfossintáticas. ALTENHOFEN, Cléo V.; KLASSMANN, Mário Silfredo; KOCH, Walter (orgs.) et al. Porto Alegre: Ed. da UFRGS; Florianópolis: Ed. da UFSC; Curitiba: Ed. da UFPR, 2002.

CAMARA JUNIOR, Joaquim Mattoso. História e estrutura da língua portuguesa. 3 ed. Rio de Janeiro: Padrão, 1979.

LOPES, Célia R. dos Santos. Nós e a gente no português falado culto do Brasil.

D.E.L.T.A, v. 14, n. 2, 1998. Disponível em:

$<\underline{\text { http: } / / \text { www.scielo.br/scielo.php?pid }=\mathrm{S} 0102-44501998000200006 \& \text { script }=\text { sci arttext }>}$

Acessado em: 10 set. 2009.

A gramaticalização de a gente em português em tempo real e de curta duração:

retenção e mudança na especificação dos traços intrínsecos. Fórum Lingüístico, v. 4, n. 1, 2007, p. 47-80.

MONTEIRO, José Lemos. Morfologia portuguesa. 4 ed. Campinas: Pontes, 2002. Pronomes pessoais: subsídios para uma gramática do português do Brasil. Fortaleza: Edições UFC, 1994.

Dialetologia e diacronia. Revista de Letras. Fortaleza, v. 14, n.1, p. 183-203, 1989. Disponível em: < http://www.geocites.com/jolemos.geo $>$ Acessado em: 10 set. 2009.

MONTEIRO, Clóvis. Da tendência analítica na evolução do nosso idioma. Rio de Janeiro: Empreza Gráfica Editora, 1926.

PINHO, Antonio José de; MARGOTTI, Felício Wessling. Aspectos de variação lexical no sul do Brasil. Interdisciplinar: revista de estudos de língua e literatura, v. 9, 2009, p. 51-66.

PINHO, Antonio José de. Um estudo diacrônico do pronome conosco. $96 \mathrm{f}$. Monografia (Conclusão de Curso Bacharelado em Letras) - Centro de Comunicação e Expressão, Universidade Federal de Santa Catarina, Florianópolis, 2009. 
SLOBIN, Dan Isaac. Psicolingüística. São Paulo: Edusp, 1980.

SILVA BRUSTOLIN, Ana Kelly Borba da. Itinerário do uso e variação de nós e a gente em textos escritos e orais de alunos do Ensino Fundamental da rede pública de Florianópolis. 250 f. Dissertação (Mestrado em Linguística) - Centro de Comunicação e Expressão, Universidade Federal de Santa Catarina, Florianópolis, 2009.

SILVA NETO, Serafim. Fontes do Latim Vulgar: o appendix Probi. Rio de Janeiro: Imprensa Nacional, 1946.

TARALLO, Fernando. Tempos lingüísticos. Sao Paulo: Ática, 1990.

VASCONCELOS, José Leite de. Textos Arcaicos. $5^{\text {a }}$ ed. Lisboa: Livraria Clássica, 1970. 